\title{
Intra-wound vancomycin powder for the eradication of periprosthetic joint infection after debridement and implant exchange: experimental study in a rat model
}

\author{
Jian Wei $^{1 \dagger}$, Kai Tong $^{2 \dagger}$, Siqi Zhou ${ }^{2}$, Hui Wang ${ }^{3}$, Yinxian Wen ${ }^{2^{*}}$ and Liaobin Chen ${ }^{2^{*}}$ (]
}

\begin{abstract}
Background: Intra-wound vancomycin powder (VP) has been used in clinical practice to prevent periprosthetic joint infection (PJI) after primary knee/hip arthroplasty. The role of intra-wound VP in the setting of debridement and implant exchange after PJI remains undefined. This study aimed to explore the efficacy and safety of intra-wound VP in the control of methicillin-resistant S. aureus (MRSA) infection after debridement and implant exchange.
\end{abstract}

Methods: PJI modeling by knee prosthesis implantation and MRSA inoculation, debridement and implant exchange were performed in Wistar rats successively to mimic the one-stage exchange arthroplasty of PJl patients. Two weeks of systemic vancomycin (SV) or/and intraoperative intra-wound VP of single dosage were applied after revision surgery.

Results: No post-surgery deaths, incision complications and signs of drug toxicity were observed. The microbial counts of SV or intra-wound VP group were significantly reduced compared with the control group, while bacteria were still detected on the bone, soft-tissue and prosthesis. The elimination of bacterial counts, along with improvement of tissue inflammation and serum inflammatory markers, were observed in the rats with SV plus intra-wound VP. Serum levels of vancomycin in all groups were lower than that of causing nephrotoxicity, while no statistic difference was observed in the serum biochemical marker among the groups.

Conclusions: Intra-wound VP is effective after debridement and implant exchange in our current rat PJI model. Neither SV nor intra-wound VP alone could eradicate the bacteria within a two-weeks treatment course, while SV plus intra-wound VP could eliminate the MRSA infection, without notable hepatic or renal toxicity and any incision complications.

Keywords: Periprosthetic joint infection, One-stage exchange arthroplasty, Intra-wound vancomycin powder, Rat model

*Correspondence: wenyinxian202102@163.com; clb202102@163.com

${ }^{\dagger}$ Jian Wei and Kai Tong contributed equally to this work.

${ }^{2}$ Division of Joint Surgery and Sports Medicine, Department

of Orthopedic Surgery, Zhongnan Hospital of Wuhan University, No.169,

Donghu Road, Wuhan 430071, China

Full list of author information is available at the end of the article

\section{Introduction}

Periprosthetic joint infection (PJI) is one of the most common causes of revision total knee/hip arthroplasty, which counts for up to $25.2 \%$ of the revision arthroplasties [1, 2]. S. aureus is one of the most common pathogens for all the PJI cases [3], while approximately $47 \%$ of $S$. aureus clinically isolated in the United States are MRSA [4]. Currently study reported that after 
revision arthroplasty of MRSA infection, the risk of failure or re-infection was much higher than methicillin-sensitive $S$. aureus [3], of which the recurrence rate of infection was up to $28.6 \%$ [5-7].

One-stage exchange arthroplasty, namely immediate implant exchange after debridement, is one of the important strategies for PJI treatment, which is praised highly by orthopedic scholars in recent years. However, the infection eradication rate was still not satisfactory, approximately $5-25 \%$ of patients failed in eliminating the infection after one-stage exchange arthroplasty [8]. In addition to complete debridement, perioperative management of antibiotics is extremely important. The current recommendation by systemic vancomycin post-surgery as the preferred therapeutic antibiotics for PJI caused by MRSA may not be adequate. Generally, systemic vancomycin fails to reach the minimum biofilm eradication concentration (MBEC) of the synovial fluid and infected tissues [9, 10], while increasing the dosage, concentration and duration of systemic vancomycin may increase the risk of drug adverse reactions. Even if vancomycincemented prosthesis was used for some single-stage exchange surgeries, vancomycin in the cement-fixation should be limited to $1-2 \mathrm{~g}$ per $40 \mathrm{~g}$ cement powder, or the mechanical properties of antibiotic-cement may be significantly decreased [11]. In addition, in vitro studies suggested that less than $5 \%$ of total vancomycin in the cement were eventually released in two-months elution [12-14]. Obviously, systemic vancomycin and/ or vancomycin-cemented prosthesis seems not the best solution for increasing the concentration of vancomycin in the synovial fluid and infected tissues around the joint. Thus, local application of antibiotics such as vancomycin attracts the attention of the surgeons currently. Some clinical studies had demonstrated that intra-wound VP could reduce the incidence of infections in the infection prophylaxis of primary knee/hip arthroplasty and spine surgery due to the high local concentration of vancomycin $[15,16]$. However, several studies suggested that intra-wound VP did not alter the infection rate but increased the incidence of wound complications [17-21]. To our knowledge, the efficacy and safety of intra-wound VP in the one-stage exchange arthroplasty has not been evaluated in the previous researches.

Herein, this study intended to explore the efficacy and safety of intra-wound VP in the PJI controlling caused by MRSA after debridement and implant exchange in a rat model, to provide experimental basis for the clinical development of postoperative antibiotic management plan.

\section{Materials and methods}

\section{Animals and reagents}

Wistar rats of SPF grade (male, aged 11 weeks, weighted $285 \mathrm{~g} \pm 6 \mathrm{~g}$ ). All animal experimental procedures were performed following the Guidelines for the Care and Use of Laboratory Animals of the Animal Welfare Committee. Clinical-grade vancomycin hydrochloride for injection was obtained from Lilly (Japan). Dosages of vancomycin were based on the vancomycin therapeutic guidelines of human and used in prior PJI patients and rat models $[15,17,22-26]$.

\section{Bacteria}

Individual colonies (MRSA; ATCC 43300) were grown in Luria-Bertani (LB) broth. When log-phase growth was achieved, bacterial suspension was centrifuged and the supernatant was discarded, bacteria were resuspended with PBS solution to achieve a concentration of approximately $1.5 \times 10^{6} \mathrm{CFU} / \mathrm{ml}$ as confirmed by serial dilution and plating on agar plates. In a pilot study, we established that $50 \mu \mathrm{l}$ of $1.5 \times 10^{6} \mathrm{CFU} / \mathrm{ml}$ ATCC 43300 inoculation was sufficient to reliably produce a PJI Wistar rats in 2 weeks. The minimal inhibitory concentration (MIC) of vancomycin in MRSA (ATCC-43300) was detected by microbroth dilution method. Vancomycin was added to 96-well plate with serial dilutions, the initial bacterial concentration in each well was adjusted to a concentration of $10^{5} \mathrm{CFU} / \mathrm{ml}$ and incubated at $37^{\circ} \mathrm{C}$ for $24 \mathrm{~h}$. The vancomycin MIC was defined as the lowest concentration that inhibited visible growth.

\section{Surgical procedure and study design}

Briefly, general anesthesia was induced by intraperitoneal administration of ketamine $(60 \mathrm{mg} / \mathrm{kg})$ and xylazine $(6 \mathrm{mg} / \mathrm{kg})$. After surgical anesthesia, the right legs of all rats were shaved, the skin was disinfected, the knee joint was surgically exposed, and a $1.3-\mathrm{mm}$ hole was drilled into the femoral canal just anterior to the Blumensaat line. The prosthesis (diameter $1.5 \mathrm{~mm}$, length $5 \mathrm{~mm}$ ) was manually placed through retrograde insertion with a screwdriver, with $1 \mathrm{~mm}$ screw cap protruding into the joint (Fig. 1). After the capsule was sutured, $50 \mu \mathrm{l}$ of $1.5 \times 10^{6} \mathrm{CFU} / \mathrm{ml}$ suspension of ATCC 43300 was injected into the articular cavity. Pain was controlled with buprenorphine within 3 days post-surgery $(0.1 \mathrm{mg} / \mathrm{kg})$. On days 14 after surgery and bacterial inoculation, X-rays showed prosthesis loosening and osteolysis (Fig. 1). The prosthesis was removed by surgery aseptically, then infected and inflammatory synovium and soft tissues were removed, the femoral canal was cleaned and slightly reamed, soaking in dilute betadine lavage for $10 \mathrm{~min}$, and washing with saline and dilute betadine repeatedly until 


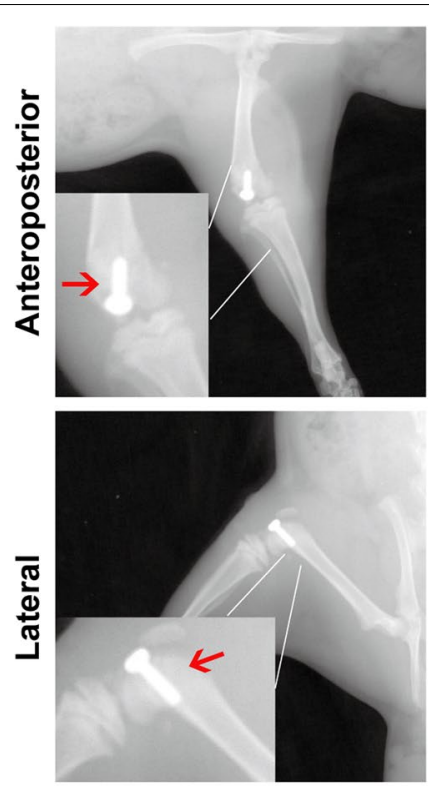

Post-implantation day 1
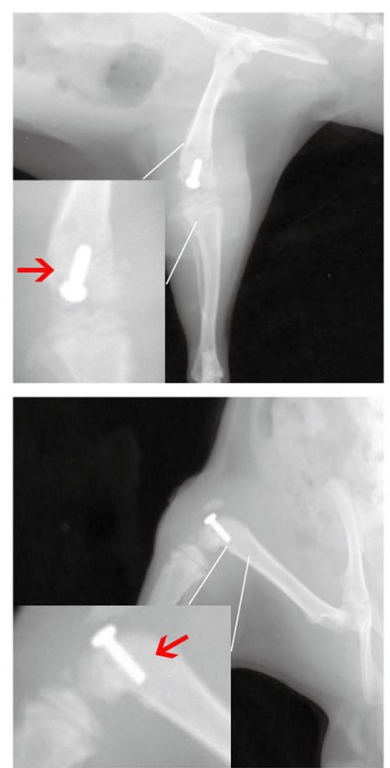

Post-implantation day 14
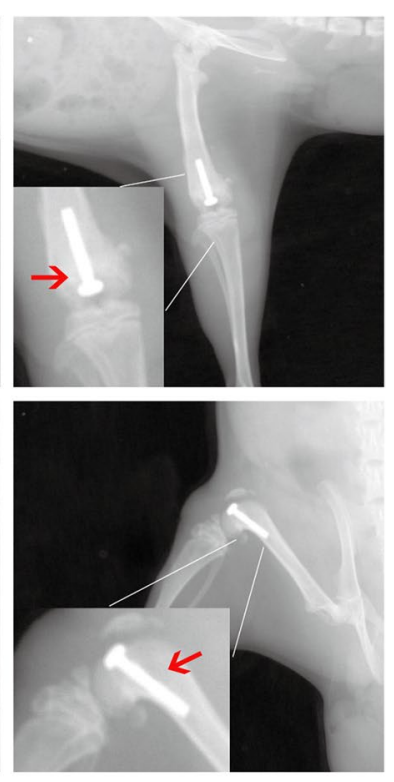

Post-revision day 1

Fig. 1 Radiological evaluation after knee prosthesis implantation (post-implantation day 1 and days 14) and one-stage exchange arthroplasty surgery (post-revision day 1). Anterior-posterior and lateral X-ray images were taken of right hind limbs of rats after knee prosthesis implantation and one-stage exchange arthroplasty to confirm the position of prosthesis and osteolysis around the prosthesis

intra-wound tissues were fresh. New elongated prosthesis (diameter $1.6 \mathrm{~mm}$, length $8 \mathrm{~mm}$ ) were implanted after debridement (Fig. 1). Sixty rats were randomly divided into four treatment groups after debridement and implant exchange: (1) Control (no antibiotics, $n=15)$, (2) systemic vancomycin (intraperitoneal injection, $88 \mathrm{mg} / \mathrm{kg}$, every $12 \mathrm{~h}$ (q12 h), $n=15$; equal to $1 \mathrm{~g}$ in a $70 \mathrm{~kg}$ patient, q12 h), (3) intra-wound VP [medullary cavity, articular cavity, prosthesis interface, synovial surface and intra-wound soft tissues were uniformly distributed] (before closure of the capsule, $88 \mathrm{mg} / \mathrm{kg}, n=15$; single dosage), and (4) systemic vancomycin \& intra-wound VP $(n=15)$. Animals that assigned to systemic vancomycin were administered for 2 weeks. All animals were euthanized on days 28 for tissue harvest in accordance with the Institutional Animal Care and Use Committee approved protocol.

\section{Serum biochemical markers and serum levels \\ of vancomycin}

Serum samples were obtained by centrifugation (3000 rpm, $\left.4^{\circ} \mathrm{C}, 15 \mathrm{~min}\right)$. The serum alpha-1-acid glycoprotein ( $\alpha 1$-AGP), creatinine (Cr), alanine aminotransferase (ALT), and aspartate aminotransferase (AST) were measured by ELISA kit (CUSABIO, China; as described in the figure legends). The serum levels of vancomycin at $0.5 \mathrm{~h}, 2 \mathrm{~h}, 4 \mathrm{~h}$ and $12 \mathrm{~h}$ after vancomycin first application were detected by high-performance liquid chromatography-mass spectrometry (HPLC-MS, Thermo TSQ Quantis, USA; filter: SRM MS2 725.80$1307.30 \mathrm{~m} / \mathrm{z}$; mass: $1307.30 \mathrm{~m} / \mathrm{z}$; retention time: $1.58 \mathrm{~min}$; solvents: $1 \%$ formic acid water and pure acetonitrile; columns: Hypersil GOLD, Thermo Fisher, $100 \times 2.1 \mathrm{~mm}$, $3 \mu \mathrm{m}$; flow rates: $0.2 \mathrm{ml} / \mathrm{min}$; time: $6 \mathrm{~min}$ ).

\section{X-ray evaluation}

Anterior-posterior and lateral X-ray images were taken from the right limbs to confirm the position of the prosthesis and the osteolysis around the prosthesis (Bruker, Germany; Filter: $0.4 \mathrm{~mm}, 45 \mathrm{kvp}$, Exposure time: $1.2 \mathrm{~s}$, Bin: $1 \times 1$ Pixels, FOV: $10 \mathrm{~cm}$, fStop: 2).

\section{Scanning Electron microscopy of prosthesis}

Prosthesis was carefully removed and the surfaces were examined by a single, experienced observer blinded to treatment. The samples were fixed $(2.5 \%$ glutaraldehyde $4{ }^{\circ} \mathrm{C} 24 \mathrm{~h}$, osmium acid $2 \mathrm{~h}$ ), dehydrated in an alcohol gradient (concentration of 50, 60, 80, 95, and 100\%, for 10 min per concentration), dried in an EM CPD300 Critical Point Dryer (Leica, Germany), coated with a conductive coating using a Q150R S Plus Sputter Coater (Quorumtech, England), and observed using Zeiss Auriga field emission scanning electron microscope (SEM) and Gatan digital camera system (Zeiss, Germany). MRSA was identified referring to the previous literature [27]. Five fields of view (FOV) were randomly selected from 
each specimen for observation under high magnification $(5000 \times)$ and MRSA in each FOV were counted.

\section{Microbiological evaluation}

On days 28, the surgical incision was reopened under sterile conditions. Sterile surgical instruments were used to harvest wound tissue, including all the muscles and soft tissue around the knee, knee joint bone, prosthesis. The tissues (bone and soft tissues) were combined with the same amount $(8 \mathrm{ml})$ of sterile PBS solution, respectively, then homogenized with a fast tissue grinder $(70 \mathrm{HZ}$, $10 \mathrm{~min}$; JXFSTPRP, China). Then, $100 \mu \mathrm{l}$ of supernatant was inoculated onto LB agar Petri dishes and grown for $24 \mathrm{~h}$ at $37^{\circ} \mathrm{C}$. The retrieved prosthesis was placed in $2 \mathrm{ml}$ of sterile PBS solution (containing 0.3\% Tween 20) and sonicated to stimulate release of bacteria biofilm from the prosthesis. $100 \mu \mathrm{l}$ of prosthesis supernatant was inoculated as prior descriptions [16, 28, 29]. Bacterial colonies were quantified using plate count method.

\section{Histopathological evaluation}

Histologic analyses (knee joint) were carried out to assess the tissue morphology with particular attention toward signs of inflammation, bone necrosis and osteomyelitis. After decalcification [0.3M EDTA, 28 days] (bone), dehydration (ethanol, xylene, and paraffin), and paraffinembedding (all samples), samples were sectioned $(4 \mu \mathrm{m})$ and stained with hematoxylin and eosin (H\&E). All the slices were observed and photographed by H550S Photo Imaging System (Nikon, Japan), and assessed by an experienced observer blinded to treatment.

\section{Statistical analysis}

Data were analyzed using SPSS software (version 22.0; SPSS Inc., USA) and are presented as the mean and standard error of the mean. Data were compared by twoway analysis of variance (ANOVA), or unpaired 1-tailed Mann-Whitney test (see figure legends). $P$ values of $<0.05$ were considered significant.

\section{Results}

\section{Assessments of serum infection biomarker}

The $\alpha 1$-AGP is a characteristic serum biomarker of acute infection in rats. The mean values of $\alpha 1$-AGP in the Control, SV, VP and SV\&VP groups were $80.31 \pm 14.33 \mu \mathrm{g} / \mathrm{ml}, 74.38 \pm 10.82 \mu \mathrm{g} / \mathrm{ml}, 78.74 \pm 7.18 \mu \mathrm{g} /$ $\mathrm{ml}$, and $75.73 \pm 16.88 \mu \mathrm{g} / \mathrm{ml}$ before surgery. On days 14 after bacterial inoculation, serum $\alpha 1$-AGP of each group were $347.32 \pm 64.43 \mu \mathrm{g} / \mathrm{ml}, \quad 351.94 \pm 67.48 \mu \mathrm{g} /$ $\mathrm{ml}, \quad 347.33 \pm 60.44 \mu \mathrm{g} / \mathrm{ml}$, and $336.31 \pm 53.85 \mu \mathrm{g} /$ $\mathrm{ml}$, respectively, which were all significantly higher than those preoperative (Fig. 2, $P<0.01$ ). On days 28 , $\alpha 1$-AGP of the Control, SV, VP and SV\&VP groups

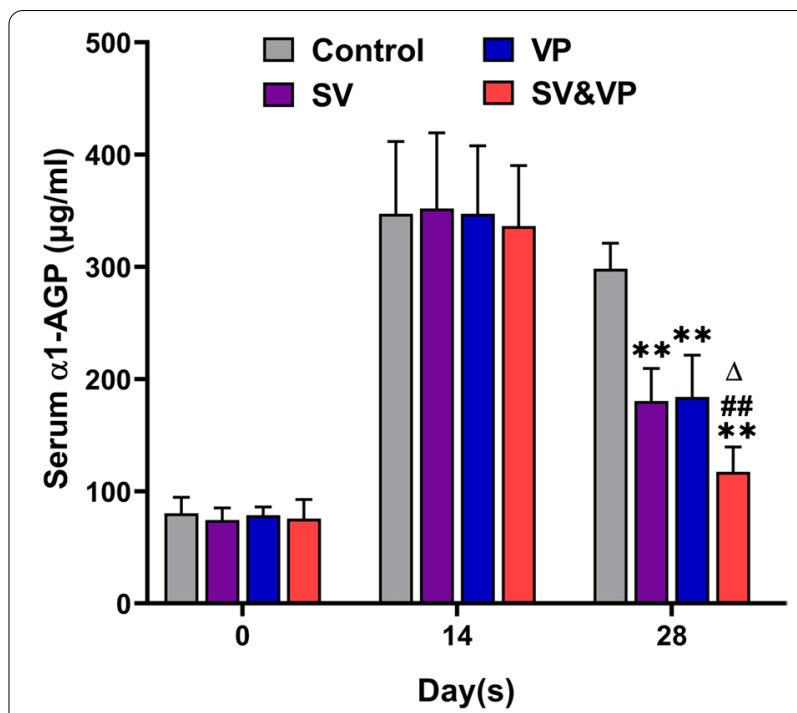

Fig. 2 The serum a1-AGP during the whole experiment (pre-operation, days 14 and 28). Control (no antibiotics); SV: Systemic vancomycin (intraperitoneal injection, $88 \mathrm{mg} / \mathrm{kg}$, every 12 h); VP: Intra-wound vancomycin powder (before closure of the capsule, $88 \mathrm{mg} / \mathrm{kg}$, single dosage); SV\&VP: Systemic vancomycin \& intra-wound VP (intraperitoneal injection, $88 \mathrm{mg} / \mathrm{kg}$, every $12 \mathrm{~h}$; combined with intra-wound VP before closure of the capsule, $88 \mathrm{mg} / \mathrm{kg}$, single dosage). ${ }^{*} P<0.01$ (Compared with Control group), ${ }^{\# \#} P<0.01$ (Compared with VP group), ${ }^{\Delta} P<0.01$ (Compared with SV group). $n=8$

were $\quad 298.30 \pm 22.71 \mu \mathrm{g} / \mathrm{ml}, \quad 168.18 \pm 26.92 \mu \mathrm{g} / \mathrm{ml}$, $176.02 \pm 38.16 \mu \mathrm{g} / \mathrm{ml}$, and $117.37 \pm 22.14 \mu \mathrm{g} / \mathrm{ml}$, respectively, indicating that $\alpha 1$-AGP in the vancomycin treatment groups were significantly lower than the Control group $(P<0.01)$. No significantly differences were detected between the SV and VP group $(P>0.05)$, while the SV \& VP group showed the lowest serum $\alpha 1$-AGP levels in all treatment groups (Fig. $2, P<0.01$ ).

\section{X-ray evaluation of the knee}

On days 14, signs of prosthesis loosening and osteolysis around the prosthesis were observed, indicating a local infection in the knee (Fig. 1). On days 28, prostheses were still in the position of distal femoral metaphysis, but all of them were accompanied by signs of prosthesis loosening and osteolysis around the prosthesis, of which the Control group was the most serious, while milder osteolysis was observed in the rats from SV, VP and SV \& VP groups, especially in the SV \& VP group (Fig. 3).

\section{Microbiological evaluation}

A greater quantity of MRSA particles was observed in the Control group, which was surrounded by host erythrocyte. No other microbial contamination was found in any field of view. Compared with the Control group, 


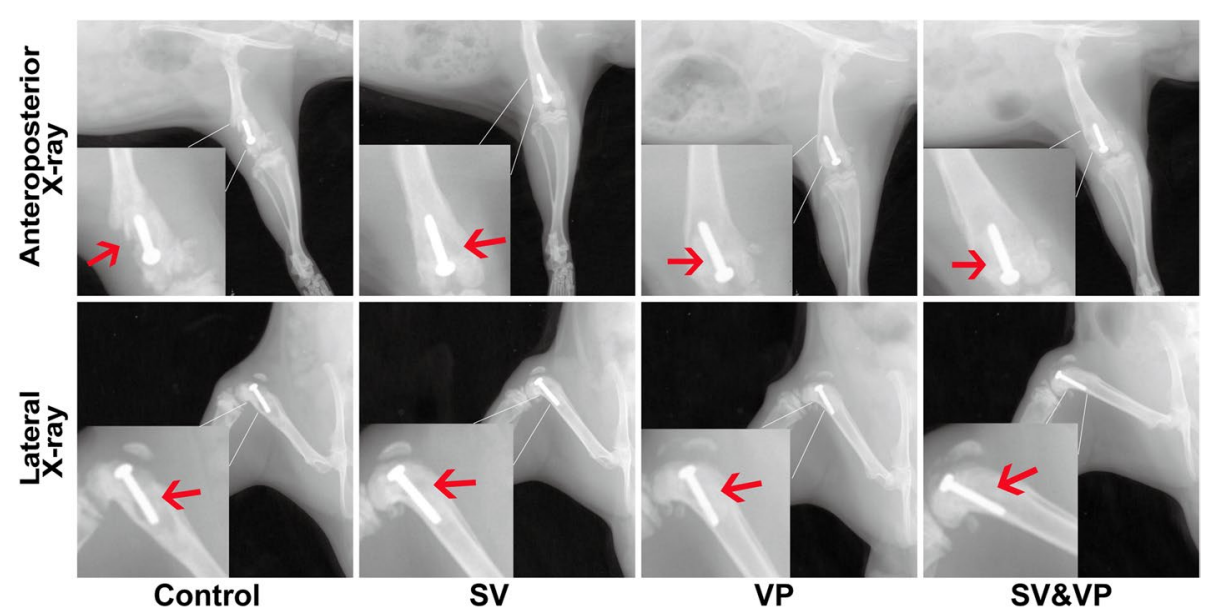

Fig. 3 X-ray evaluation of the knee joint and prosthesis on days 28. Control (no antibiotics); SV: Systemic vancomycin (intraperitoneal injection, $88 \mathrm{mg} / \mathrm{kg}$, every $12 \mathrm{~h}$ ); VP: Intra-wound vancomycin powder (before closure of the capsule, $88 \mathrm{mg} / \mathrm{kg}$, single dosage); SV\&VP: Systemic vancomycin \& intra-wound VP (intraperitoneal injection, $88 \mathrm{mg} / \mathrm{kg}$, every $12 \mathrm{~h}$; combined with intra-wound VP before closure of the capsule, $88 \mathrm{mg} / \mathrm{kg}$, single dosage). The red arrow indicates the position of prosthesis and destruction of the bone

bacterial counts on the prostheses in the SV, VP and SV \& VP groups were decreased, while no bacteria were observed in the SV \& VP group (namely the bacteria on the surface of prosthesis were completely eliminated) (Fig. 4A-B). The bacterial colonies of each specimen and the whole animal in each treatment group were shown in Table 1 and Fig. 4C-F. The average CFUs of each specimen in vancomycin treatment groups were significantly less than the Control group, bacterial counts and whole animal in the SV group were less than the VP group, both of the SV and VP groups were higher than that of the SV \& VP group, as no bacterial colonies were observed in any specimen in the SV \& VP group (Fig. 4 C-F, $P<0.01$ ).

\section{Tissue inflammation evaluation}

Osteomyelitis changes were observed in the Control animals, such as intramedullary abscess, necrotic bone formation, trabecular bone structure changes and inflammatory cell aggregation, while all these changes were attenuated after vancomycin treatment, especially in the SV\&VP group. Almost no obvious inflammatory cells infiltration was observed in the SV\&VP group (Fig. 5).

\section{Safety evaluation of intra-wound VP or/and systemic vancomycin in one-stage exchange arthroplasty}

Macroscopically, the incisions of each group were healed without wound rupture or exudation. The serum levels of vancomycin in the SV, VP and SV \& VP groups were all higher than the MIC of MRSA (ATCC 43300; $2 \mu \mathrm{g} / \mathrm{ml}$ ) at $0.5 \mathrm{~h}$ after vancomycin administration, but lower than the serum level that could cause nephrotoxicity $(15-20 \mu \mathrm{g} /$ $\mathrm{ml}$ ) [30-33]. At post-surgery $12 \mathrm{~h}$, the serum levels of the vancomycin treatment groups were lower than the limit of detection (Table 2). Moreover, the serum Cr, ALT and AST of each treatment group were all within the normal range, while no significant difference was observed among the four groups on days 28 and pre-operative values (Fig. $6, P>0.05$ ).

\section{Discussion}

Vancomycin is usually used in the treatment MRSA infections by inhibiting cell wall synthesis in Gram-positive bacteria. The traditional post-revision surgery administration of MRSA PJI relies on the effects of intravenous systemic vancomycin and follow by long-term oral antibiotics. The MBEC of vancomycin required to eliminate the MRSA biofilms of the prosthesis and infected tissue was up to $10^{2}$ to $10^{4}$ times of the MIC $[34,35]$. Obviously, systemic vancomycin could hardly meet the requirement of eradicating MRSA infection in a short period [9]. In recent years, orthopedic surgeons tried to apply intra-articular vancomycin (injection or powder), or/and systemic vancomycin, to control the clinical MRSA infection after one-stage exchange arthroplasty [36-39]. However, these studies are essentially empirical retrospective case reports from a single orthopedic center. The theory of local high concentrations of antibiotics is that antibiotics may permeate into the surgical sites of seroma, hematoma and ischemic tissues that may be inaccessible by systemic antibiotics $[9,40]$. Compared with intraarticular injection of vancomycin, intra-wound VP did not require long-term injection of catheters or drainage tube. Besides, daily post-operative intra-articular injections for 4-6weeks or even longer which was reported in 


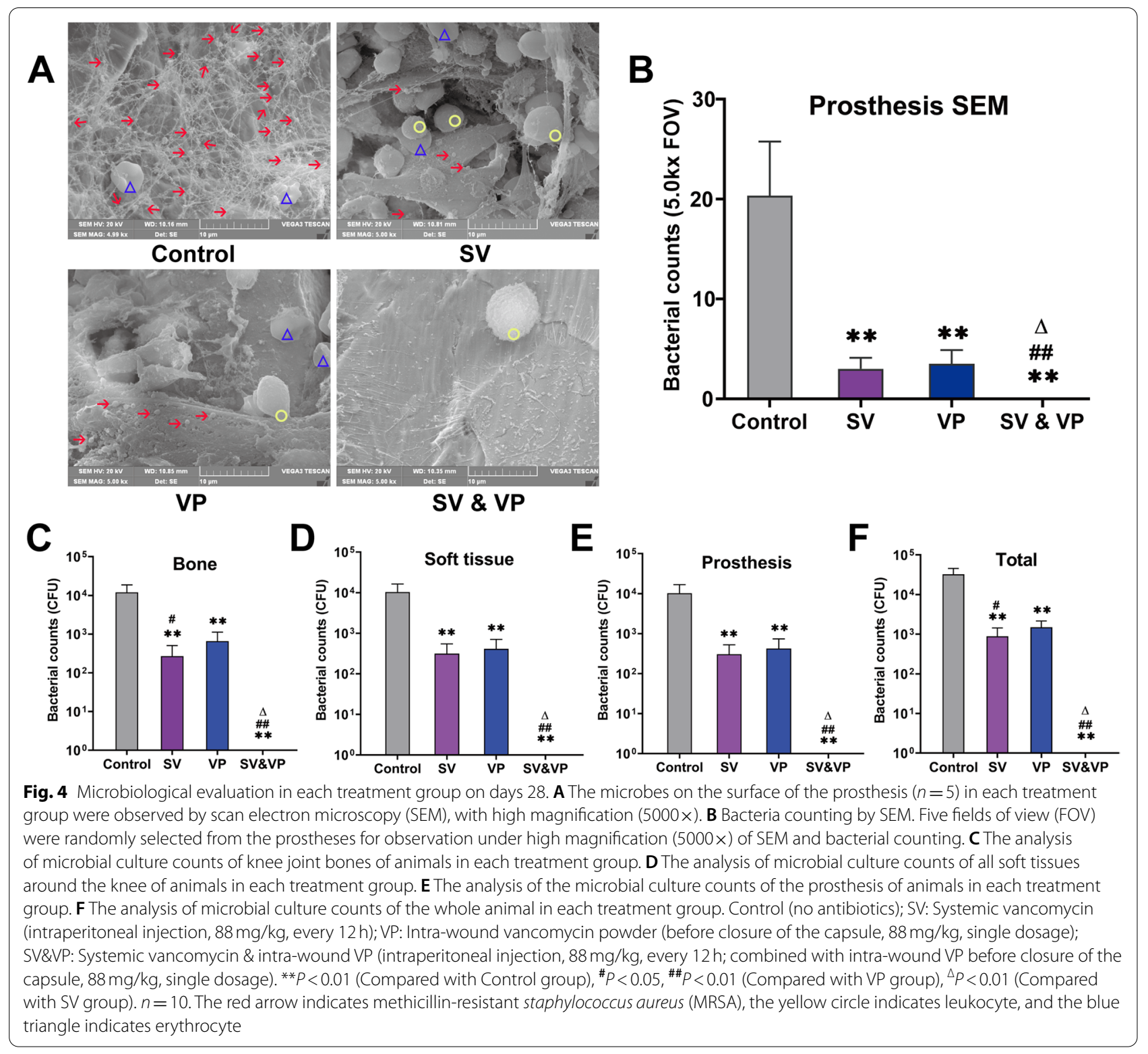

Table 1 Mean colony-forming units (CFUs) data from Fig. 4C-F

\begin{tabular}{lllll}
\hline Group & Bone & Prosthesis & Soft tissue & Total \\
\hline Control & $1.19 \times 10^{4} \pm 6.76 \times 10^{3}$ & $1.03 \times 10^{4} \pm 5.93 \times 10^{3}$ & $1.02 \times 10^{4} \pm 6.51 \times 10^{3}$ & $3.26 \times 10^{4} \pm 1.32 \times 10^{4}$ \\
SV & $269 \pm 237$ & $313 \pm 234$ & $307 \pm 219$ & $889 \pm 549$ \\
VP & $660 \pm 469$ & $414 \pm 292$ & $427 \pm 313$ & $1501 \pm 658$ \\
SV\&VP & 0 & 0 & 0 & 0 \\
\hline
\end{tabular}

Control (no antibiotics); SV Systemic vancomycin (intraperitoneal injection, $88 \mathrm{mg} / \mathrm{kg}$, every $12 \mathrm{~h}$ ), VP Intra-wound vancomycin powder (before closure of the capsule, $88 \mathrm{mg} / \mathrm{kg}$, single dosage), SV\&VP Systemic vancomycin \& intra-wound VP (intraperitoneal injection, $88 \mathrm{mg} / \mathrm{kg}$, every $12 \mathrm{~h}$; combined with intra-wound VP before closure of the capsule, $88 \mathrm{mg} / \mathrm{kg}$, single dosage). $n=10$ 


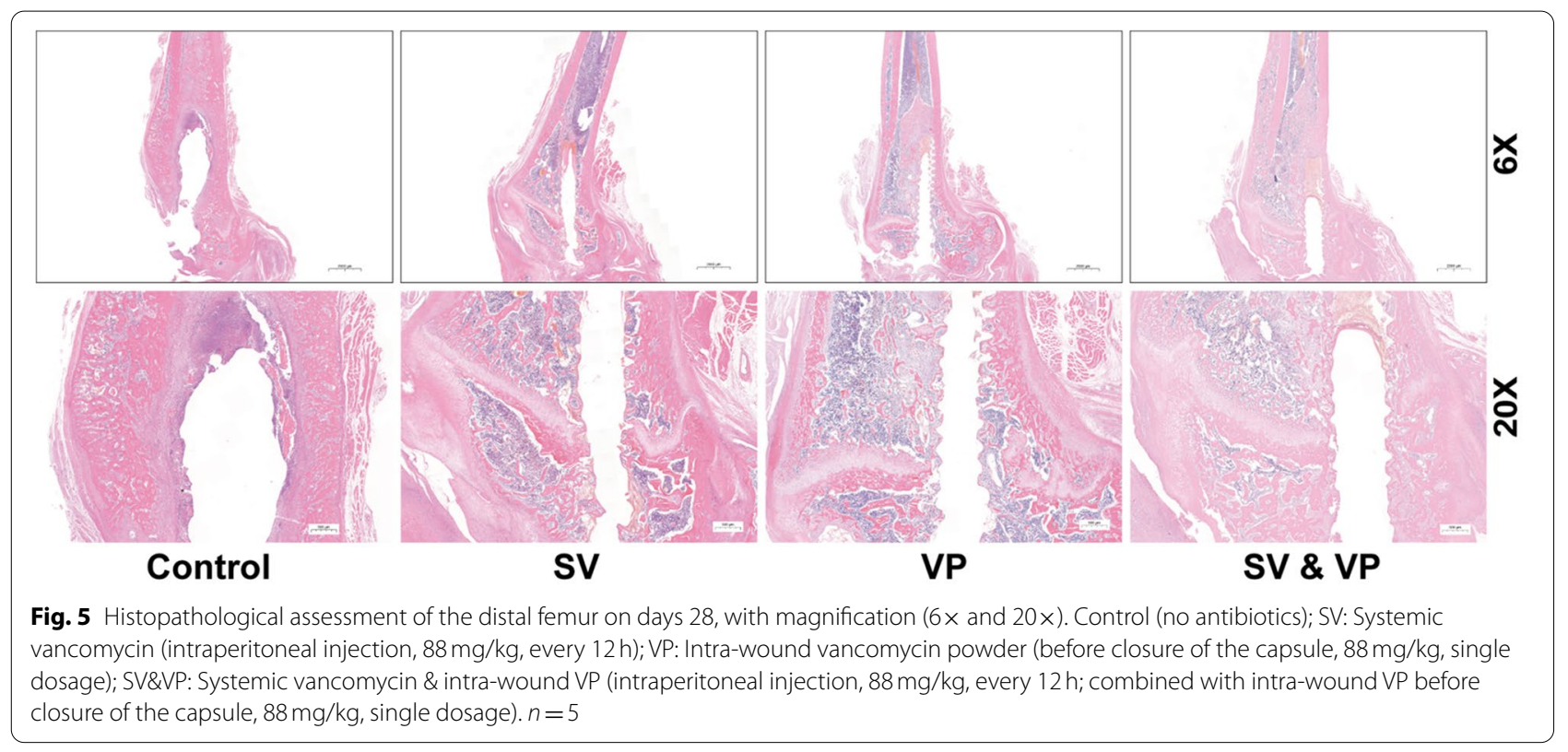

Table 2 Serum levels of vancomycin at 0.5, 2, 4 and $12 \mathrm{~h}$ after vancomycin treatment in each group $(\mu \mathrm{g} / \mathrm{ml})$

\begin{tabular}{lllll}
\hline Group & $\mathbf{0 . 5 h}$ & $\mathbf{2 h}$ & $\mathbf{4 h}$ & $\mathbf{1 2 h}$ \\
\hline Control & 0 & 0 & 0 & 0 \\
SV & $10.21 \pm 1.79$ & $3.32 \pm 0.58$ & $0.48 \pm 0.03$ & $\#$ \\
VP & $2.68 \pm 0.32$ & $0.71 \pm 0.08$ & $0.50 \pm 0.04$ & $\#$ \\
SV\&VP & $14.14 \pm 1.18$ & $7.49 \pm 0.62$ & $1.40 \pm 0.23$ & $\#$ \\
\hline
\end{tabular}

Control (no antibiotics); SV Systemic vancomycin (intraperitoneal injection, $88 \mathrm{mg} / \mathrm{kg}$, every $12 \mathrm{~h}$ ), VP Intra-wound vancomycin powder (before closure of the capsule, $88 \mathrm{mg} / \mathrm{kg}$, single dosage), SV\&VP Systemic vancomycin \& intra-wound VP (intraperitoneal injection, $88 \mathrm{mg} / \mathrm{kg}$, every $12 \mathrm{~h}$; combined with intra-wound VP before closure of the capsule, $88 \mathrm{mg} / \mathrm{kg}$, single dosage). $n=6$. \# Below the limit of detection $(0.1 \mu \mathrm{g} / \mathrm{ml})$ the available literature $[37,41]$ are unlikely to be implemented in clinical practice because of the fear of secondary infection or complications of the catheter incision through the injection channel. Thus, intra-articular catheter injection of vancomycin seems not to be the best way to achieve the MBEC in the synovial fluid and infected tissues after one-stage exchange arthroplasty. Although our results indicated that intra-wound VP alone could not eliminate the bacteria, it might be an important complement to systemic administration. When systemic vancomycin in combination with intra-wound VP could eradicate MRSA infection within a short period as confirmed by our current study. Our data suggested that systemic vancomycin plus intra-wound VP might be an

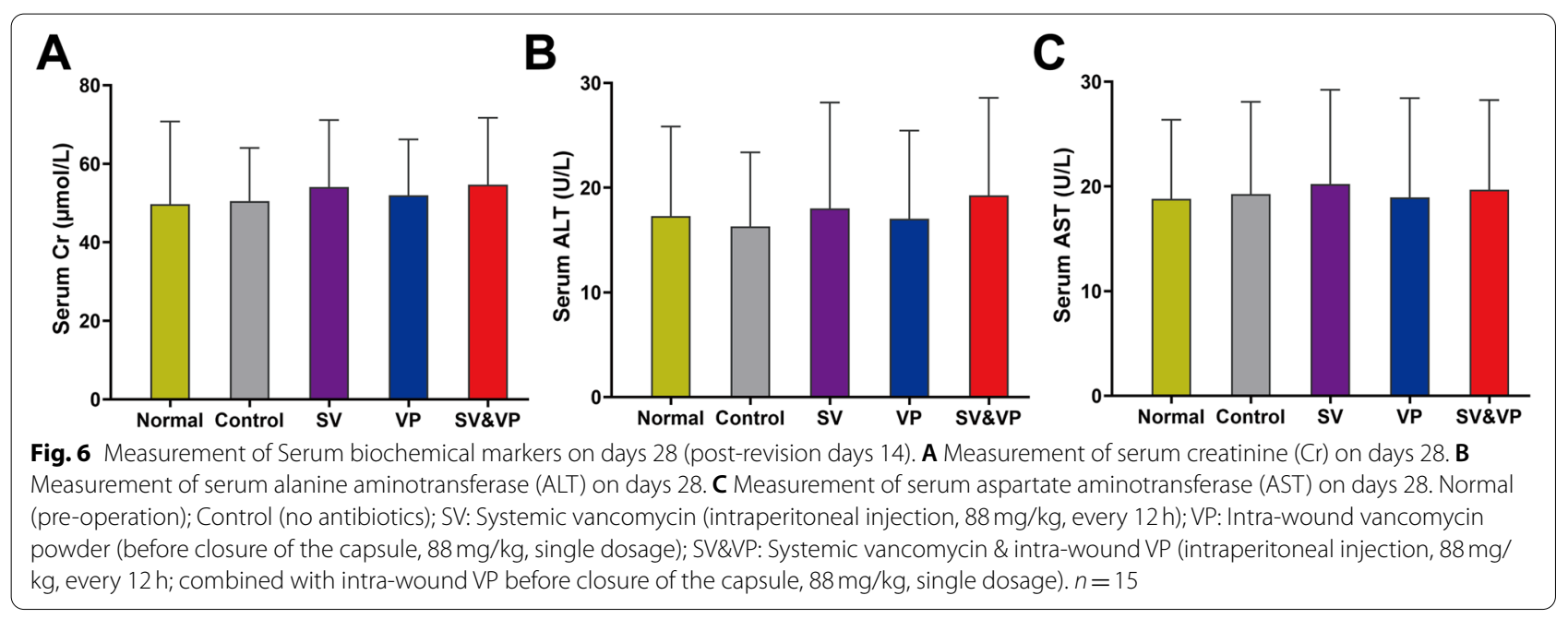


effective way to eliminate MRSA infection after one-stage exchange arthroplasty in 2 weeks in our current rat PJI model.

The most commonly reported adverse effects of vancomycin used in human are nephrotoxicity and ototoxicity. Clinical nephrotoxicity of routine systemic vancomycin which have been reported ranged from 0 to $17 \%$ [4244]. In this study, no adverse effects of vancomycin were observed in serum biochemistry between the Control group and vancomycin therapeutic groups. Meanwhile, our data also indicated that the serum levels of vancomycin in the treatment groups were all higher than the MIC of MRSA at $0.5 \mathrm{~h}$ after administration, but lower than the serum level that could cause nephrotoxicity. Another concern is the osteoblasts toxicity caused by local high concentrations of vancomycin, studies have showed that high dosage of antibiotics such as fluoroquinolone in surgical area could delay bone healing and repairing, with vancomycin being less toxic than ciprofloxacin or tobramycin [45]. On the base of the previous literature, if the concentration of vancomycin was less than $1 \mathrm{mg} / \mathrm{ml}$, the toxicity to osteoblasts growth and activity was minimum at the cellular level [46-48]. The available literature indicated that osteolytic damage was not observed in the intra-wound application of VP. Besides, the introduction of a crystalline substance (such as vancomycin powder) into the prosthetic interface caused concern about thirdbody wear. However, an in vitro mechanical study had demonstrated no acceleration in the prosthetic interface wear by VP [49]. Furthermore, one concern is the seroma formation with the local vancomycin treatment, a clinical study suggested that there was no significant difference in seroma formation between the control group and intraarticular VP group [15]. Although the local or systemic adverse effects of vancomycin were not observed in our study, the potential effects still existed. Further investigations and summary of drug-toxicity and the effect on metal-polyethylene wear in future clinical applications remain necessary.

However, there are still some limitations in this study. Firstly, our data were based on the uncemented prosthesis, which might lead to the prosthesis loosening and osteolysis around the prosthesis on the early stage after surgery. Thus, the prosthesis loosening and osteolysis around the prosthesis by the micromovement of the prosthesis itself might accelerate the osteolysis caused by the bacteria alone. Further studies are needed to explore the prosthesis loosening and osteolysis by using the cemented prosthesis. Secondly, the absorption, distribution, metabolism and excretion of drugs in the murine is not the same as the humans, the biodynamics and biomechanics of the rat knee is also not the same as human's, which means the current rat-based study could not exactly mimic the PJI occurred in the patients with arthroplasty surgery. Further clinical observation and study are needed to maintain more direct evidence of the effectiveness and safety of the VP in the onestage exchange surgery. Thirdly, the 14-day systemic vancomycin treatment post-exchange surgery may be inadequate, but the elimination of MRSA infection had been observed for this duration in the SV\&VP group. Lastly, our study focused on the efficacy of intra-wound VP after debridement and implant exchange, without including adjuvant oral antibiotics, such as rifampin. Further studies are needed in the future.

In conclusion, in the current rat PJI model, intrawound vancomycin powder is effective and safe to control the infection after debridement and implant exchange, while the combination of systemic vancomycin and intra-wound VP can completely eradicate the MRSA infection. Our experiment data support the potential clinical application of systemic vancomycin plus intra-wound vancomycin powder in the one-stage revision surgery. More clinical trials and follow-ups are needed in the future.

\begin{abstract}
Abbreviations
VP: Vancomycin powder; PJl: Periprosthetic joint infection; MRSA: Methicillinresistant S. aureus; MBEC: Minimum biofilm eradication concentration; MIC: Minimal inhibitory concentration; a1-AGP: Alpha-1-acid glycoprotein; $\mathrm{Cr}$ : Creatinine; ALT: Alanine aminotransferase; AST: Aspartate aminotransferase; HPLC-MS: High-performance liquid chromatography-mass spectrometry; SEM: Scanning electron microscopy; H\&E: Hematoxylin and eosin.
\end{abstract}

\section{Acknowledgments}

We thank Mrs. Qi Yin from the microbiology laboratory of Zhongnan Hospital of Wuhan University of China for MRSA (ATCC-43300).

\section{Authors' contributions}

Jian Wei designed and performed the research, analyzed the data and prepared the manuscript. Kai Tong and Siqi Zhou performed the research, too. Hui Wang, Yinxian Wen and Liaobin Chen designed the research, analyzed the data and revised the paper. The author(s) read and approved the final manuscript.

\section{Funding}

This work was supported by grants from the National Natural Science Foundation of China (No. 81673490, 81673524, 81603214, 81972036), and the Key Research and Development Project of Hubei province (No. 2020BCA071).

Availability of data and materials

All relevant data analyzed during the current study are within the paper.

\section{Declarations}

Ethics approval and consent to participate

All rat studies to have been performed in accordance with the ethical standards in the 1964 Declaration of Helsinki. The protocol of all animal experiments was approved by the Committee on the Ethics of Animal Experiments of the School of Medicine, Wuhan University (No. AF339). The study was carried out in compliance with the ARRIVE guidelines.

Consent for publication

Not applicable. 


\section{Competing interests}

The authors declare that they have no competing interests.

\section{Author details}

${ }^{1}$ Department of Joint Orthopedics, Affiliated Liutie Central Hospital of Guangxi Medical University, Liuzhou 545007, China. ${ }^{2}$ Division of Joint Surgery and Sports Medicine, Department of Orthopedic Surgery, Zhongnan Hospital of Wuhan University, No.169, Donghu Road, Wuhan 430071, China. ${ }^{3}$ Department of pharmacology, Basic Medical School of Wuhan University, Wuhan 430071, China.

Received: 21 August 2021 Accepted: 19 November 2021

Published online: 07 December 2021

\section{References}

1. Bozic KJ, Kurtz SM, Lau E, Ong K, Chiu V, Vail TP, et al. The epidemiology of revision total knee arthroplasty in the United States. Clin Orthop Relat Res. 2010;468(1):45-51. https://doi.org/10.1007/s1 1999-009-0945-0.

2. Bozic KJ, Kurtz SM, Lau E, Ong K, Vail TP, Berry DJ. The epidemiology of revision total hip arthroplasty in the United States. J Bone Joint Surg Am. 2009;91(1):128-33. https://doi.org/10.2106/JBJS.H.00155.

3. Hischebeth GT, Randau TM, Ploeger MM, Friedrich MJ, Kaup E, Jacobs C, et al. Staphylococcus aureus versus Staphylococcus epidermidis in periprosthetic joint infection-outcome analysis of methicillin-resistant versus methicillin-susceptible strains. Diagn Microbiol Infect Dis. 2019;93(2):125-30. https://doi.org/10.1016/j.diagmicrobio.2018.08.012.

4. Garvin KL, Hinrichs SH, Urban JA. Emerging antibiotic-resistant bacteria. Their treatment in total joint arthroplasty. Clin Orthop Relat Res. 1999:369:110-23.

5. Petis SM, Abdel MP, Perry KI, Mabry TM, Hanssen AD, Berry DJ. Long-term results of a 2-stage exchange protocol for Periprosthetic joint infection following Total hip arthroplasty in 164 hips. J Bone Joint Surg Am. 2019;101(1):74-84. https://doi.org/10.2106/JBJS.17.01103.

6. Cochran AR, Ong KL, Lau E, Mont MA, Malkani AL. Risk of reinfection after treatment of infected Total knee arthroplasty. J Arthroplast. 2016;31(9 Suppl):156-61. https://doi.org/10.1016/j.arth.2016.03.028.

7. Santoso A, Yoon TR, Park KS, Anwar IB, Utomo P, Soetjahjo B, et al. The results of two-stage revision for methicillin-resistant Periprosthetic joint infection (PJI) of the hip. Malays Orthop J. 2020;14(1):18-23. https://doi. org/10.5704/MOJ.2003.003.

8. Bialecki J, Bucsi L, Fernando N, Foguet P, Guo S, Haddad F, et al. Hip and knee section, treatment, one stage exchange: proceedings of international consensus on orthopedic infections. J Arthroplast. 2019;34(2S):S421-S6. https://doi.org/10.1016/j.arth.2018.09.026.

9. Roy ME, Peppers MP, Whiteside LA, Lazear RM. Vancomycin concentration in synovial fluid: direct injection into the knee vs. intravenous infusion. J Arthroplast. 2014;29(3):564-8. https://doi.org/10.1016/j.arth.2013.08.017.

10. Elkins JM, Kates S, Lange J, Lange J, Lichstein P, Otero J, et al. General assembly, diagnosis, definitions: proceedings of international consensus on orthopedic infections. J Arthroplast. 2019;34(2S):S181-S5. https://doi. org/10.1016/j.arth.2018.09.069.

11. Bistolfi A, Ferracini R, Albanese C, Verne E, Miola M. PMMA-based bone cements and the problem of joint arthroplasty infections: status and new perspectives. Materials (Basel, Switzerland). 2019;12(23). https://doi.org/ 10.3390/ma12234002

12. Bishop AR, Kim S, Squire MW, Rose WE, Ploeg HL. Vancomycin elution, activity and impact on mechanical properties when added to orthopedic bone cement. J Mech Behav Biomed Mater. 2018;87:80-6. https://doi. org/10.1016/j.jmbbm.2018.06.033.

13. Slane J, Gietman B, Squire M. Antibiotic elution from acrylic bone cement loaded with high doses of tobramycin and vancomycin. J Orthop Res. 2018;36(4):1078-85. https://doi.org/10.1002/jor.23722.

14. Li T, Fu L, Wang J, Shi Z. High dose of vancomycin plus gentamicin incorporated acrylic bone cement decreased the elution of vancomycin. Infect Drug Resist. 2019;12:2191-9. https://doi.org/10.2147/IDR.S203740.

15. Patel NN, Guild GN 3rd, Kumar AR. Intrawound vancomycin in primary hip and knee arthroplasty: a safe and cost-effective means to decrease early periprosthetic joint infection. Arthroplast Today. 2018;4(4):479-83. https:// doi.org/10.1016/j.artd.2018.07.011.
16. Zebala LP, Chuntarapas T, Kelly MP, Talcott M, Greco S, Riew KD. Intrawound vancomycin powder eradicates surgical wound contamination: an in vivo rabbit study. J Bone Joint Surg Am. 2014;96(1):46-51. https://doi.org/10.2106/JBJS.L.01257.

17. Dial BL, Lampley AJ, Green CL, Hallows R. Intrawound vancomycin powder in primary Total hip arthroplasty increases rate of sterile wound complications. Hip Pelvis. 2018;30(1):37-44. https://doi.org/10.5371/hp. 2018.30.1.37.

18. Tubaki VR, Rajasekaran S, Shetty AP. Effects of using intravenous antibiotic only versus local intrawound vancomycin antibiotic powder application in addition to intravenous antibiotics on postoperative infection in spine surgery in 907 patients. Spine (Phila Pa 1976). 2013;38(25):2149-55. https://doi.org/10.1097/BRS.0000000000000015.

19. Horii C, Yamazaki T, Oka H, Azuma S, Ogihara S, Okazaki R, et al. Does intrawound vancomycin powder reduce surgical site infection after posterior instrumented spinal surgery? A propensity score-matched analysis. Spine J. 2018;18(12):2205-12. https://doi.org/10.1016/j.spinee.2018.04. 015.

20. Hanada M, Nishikino S, Hotta K, Furuhashi H, Hoshino H, Matsuyama Y. Intrawound vancomycin powder increases post-operative wound complications and does not decrease periprosthetic joint infection in primary total and unicompartmental knee arthroplasties. Knee Surg Sports Traumatol Arthrosc. 2019;27(7):2322-7. https://doi.org/10.1007/ s00167-019-05498-Z.

21. Yavuz IA, Oken OF, Yildirim AO, Inci F, Ceyhan E, Gurhan U. No effect of vancomycin powder to prevent infection in primary total knee arthroplasty: a retrospective review of 976 cases. Knee Surg Sports Traumatol Arthrosc. 2020;28(9):3055-60. https://doi.org/10.1007/ s00167-019-05778-8.

22. Rybak MJ, Lomaestro BM, Rotschafer JC, Moellering RC, Craig WA, Billeter $M$, et al. Vancomycin therapeutic guidelines: a summary of consensus recommendations from the infectious diseases Society of America, the American Society of Health-System Pharmacists, and the Society of Infectious Diseases Pharmacists. Clin Infect Dis. 2009;49(3):325-7. https://doi. org/10.1086/600877.

23. Reagan-Shaw $S$, Nihal $M$, Ahmad N. Dose translation from animal to human studies revisited. FASEB J. 2008;22(3):659-61. https://doi.org/10. 1096/fj.07-9574LSF

24. O'Donnell JN, Rhodes NJ, Miglis CM, Catovic L, Liu J, Cluff C, et al. Dose, duration, and animal sex predict vancomycin-associated acute kidney injury in preclinical studies. Int J Antimicrob Agents. 2018;51(2):239-43. https://doi.org/10.1016/j.ijantimicag.2017.08.012.

25. Rhodes NJ, Prozialeck WC, Lodise TP, Venkatesan N, O'Donnell JN, Pais G, et al. Evaluation of vancomycin exposures associated with elevations in novel urinary biomarkers of acute kidney injury in vancomycin-treated rats. Antimicrob Agents Chemother. 2016;60(10):5742-51. https://doi.org/ 10.1128/AAC.00591-16.

26. Wei J, Wen Y, Tong K, Wang H, Chen L. Local application of vancomycin in one-stage revision of PJ caused by MRSA in a rat model. Antimicrob Agents Chemother. 2021:AAC0030321. https://doi.org/10.1128/AAC. 00303-21.

27. Carli AV, Bhimani S, Yang X, Shirley MB, de Mesy Bentley KL, Ross FP, et al. Quantification of Peri-implant bacterial load and in vivo biofilm formation in an innovative, clinically representative mouse model of Periprosthetic joint infection. J Bone Joint Surg Am. 2017;99(6):e25. https://doi.org/10. 2106/JBJS.16.00815

28. Bernthal NM, Stavrakis Al, Billi F, Cho JS, Kremen TJ, Simon SI, et al. A mouse model of post-arthroplasty Staphylococcus aureus joint infection to evaluate in vivo the efficacy of antimicrobial implant coatings. PLoS One. 2010;5(9):e12580. https://doi.org/10.1371/journal.pone.0012580.

29. Morris JL, Letson HL, Grant A, Wilkinson M, Hazratwala K, McEwen P. Experimental model of peri-prosthetic infection of the knee caused by Staphylococcus aureus using biomaterials representative of modern TKA. Biol Open. 2019;8(9). https://doi.org/10.1242/bio.045203.

30. Lodise TP, Patel N, Lomaestro BM, Rodvold KA, Drusano GL. Relationship between initial vancomycin concentration-time profile and nephrotoxicity among hospitalized patients. Clin Infect Dis. 2009;49(4):507-14. https://doi.org/10.1086/600884.

31. Alvarez R, Lopez Cortes LE, Molina J, Cisneros JM, Pachon J. Optimizing the clinical use of vancomycin. Antimicrob Agents Chemother. 2016;60(5):2601-9. https://doi.org/10.1128/AAC.03147-14. 
32. Bosso JA, Nappi J, Rudisill C, Wellein M, Bookstaver PB, Swindler J, et al. Relationship between vancomycin trough concentrations and nephrotoxicity: a prospective multicenter trial. Antimicrob Agents Chemother. 2011;55(12):5475-9. https://doi.org/10.1128/AAC.00168-11.

33. Carreno JJ, Jaworski A, Kenney RM, Davis SL. Comparative incidence of nephrotoxicity by age group among adult patients receiving vancomycin. Infect Dis Ther. 2013;2(2):201-8. https://doi.org/10.1007/ s40121-013-0022-6.

34. Bjarnsholt T, Ciofu O, Molin S, Givskov M, Hoiby N. Applying insights from biofilm biology to drug development - can a new approach be developed? Nat Rev Drug Discov. 2013;12(10):791-808. https://doi.org/ $10.1038 /$ nrd 4000

35. Zimmerli W, Trampuz A, Ochsner PE. Prosthetic-joint infections. N Engl J Med. 2004;351(16):1645-54. https://doi.org/10.1056/NEJMra040181.

36. Whiteside LA, Peppers M, Nayfeh TA, Roy ME. Methicillin-resistant Staphylococcus aureus in TKA treated with revision and direct intra-articular antibiotic infusion. Clin Orthop Relat Res. 2011;469(1):26-33. https://doi. org/10.1007/s11999-010-1313-9.

37. Whiteside LA, Roy ME. One-stage revision with catheter infusion of intraarticular antibiotics successfully treats infected THA. Clin Orthop Relat Res. 2017;475(2):419-29. https://doi.org/10.1007/ s11999-016-4977-y.

38. Ji B, Li G, Zhang X, Wang Y, Mu W, Cao L. Effective treatment of singlestage revision using intra-articular antibiotic infusion for culture-negative prosthetic joint infection. Bone Joint J. 2020;102-B(3):336-44. https://doi. org/10.1302/0301-620X.102B3.BJJ-2019-0820.R1.

39. Ji B, Zhang X, Xu B, Guo W, Mu W, Cao L. Single-stage revision for chronic fungal Periprosthetic joint infection: an average of 5 years of follow-up. J Arthroplast. 2017;32(8):2523-30. https://doi.org/10.1016/j.arth.2017.03. 030.

40. Hanssen AD, Osmon DR, Patel R. Local antibiotic delivery systems: where are we and where are we going? Clin Orthop Relat Res. 2005;437:111-4.

41. Whiteside LA, Roy ME, Nayfeh TA. Intra-articular infusion: a direct approach to treatment of infected total knee arthroplasty. Bone Joint J. 2016;98-B(1 Suppl A):31-6. https://doi.org/10.1302/0301-620X.98B.36276.

42. Farber BF, Moellering RC Jr. Retrospective study of the toxicity of preparations of vancomycin from 1974 to 1981. Antimicrob Agents Chemother. 1983;23(1):138-41. https://doi.org/10.1128/aac.23.1.138.

43. Mellor JA, Kingdom J, Cafferkey M, Keane CT. Vancomycin toxicity: a prospective study. J Antimicrob Chemother. 1985;15(6):773-80. https:// doi.org/10.1093/jac/15.6.773.

44. Sorrell TC, Collignon PJ. A prospective study of adverse reactions associated with vancomycin therapy. J Antimicrob Chemother. 1985;16(2):23541. https://doi.org/10.1093/jac/16.2.235.

45. Antoci V Jr, Adams CS, Hickok NJ, Shapiro IM, Parvizi J. Antibiotics for local delivery systems cause skeletal cell toxicity in vitro. Clin Orthop Relat Res. 2007;462:200-6. https://doi.org/10.1097/BLO.0b013e31811ff866.

46. Perry AC, Prpa B, Rouse MS, Piper KE, Hanssen AD, Steckelberg JM, et al. Levofloxacin and trovafloxacin inhibition of experimental fracture-healing. Clin Orthop Relat Res. 2003;414:95-100. https://doi.org/10.1097/01. blo.0000087322.60612.14

47. Isefuku S, Joyner CJ, Simpson AH. Gentamicin may have an adverse effect on osteogenesis. J Orthop Trauma. 2003;17(3):212-6. https://doi.org/10. 1097/00005131-200303000-00010.

48. Holtom PD, Pavkovic SA, Bravos PD, Patzakis MJ, Shepherd LE, Frenkel B. Inhibitory effects of the quinolone antibiotics trovafloxacin, ciprofloxacin, and levofloxacin on osteoblastic cells in vitro. J Orthop Res. 2000;18(5):721-7. https://doi.org/10.1002/jor.1100180507.

49. Qadir R, Ochsner JL, Chimento GF, Meyer MS, Waddell B, Zavatsky JM. Establishing a role for vancomycin powder application for prosthetic joint infection prevention-results of a wear simulation study. J Arthroplast. 2014;29(7):1449-56. https://doi.org/10.1016/j.arth.2014.02.012.

\section{Publisher's Note}

Springer Nature remains neutral with regard to jurisdictional claims in published maps and institutional affiliations.

Ready to submit your research? Choose BMC and benefit from:

- fast, convenient online submission

- thorough peer review by experienced researchers in your field

- rapid publication on acceptance

- support for research data, including large and complex data types

- gold Open Access which fosters wider collaboration and increased citations

- maximum visibility for your research: over 100M website views per year

At BMC, research is always in progress.

Learn more biomedcentral.com/submissions 